\title{
PEMERIKSAAN PAJAK DAN SANKSI PAJAK TERHADAP KEPATUHAN WAJIB PAJAK BADAN PADA KPP KEPANJEN KABUPATEN MALANG
}

\author{
Pujo Gunarso \\ Fakultas Ekonomi dan Bisnis Universitas Merdeka Malang \\ Jl. Terusan Raya Dieng 62-64 Malang
}

\begin{abstract}
This study was conducted in 2015 on the territory of the Tax Office Primary Kepanjen region. The purpose of this study is to examine the effect of tax audits and tax penalties for mandatory compliance body. Method and data analysis which was used in this research was multiple linear regression analysis, the statistical test that consists of the calculation of validity, reliability, classical assumptions, regression, coefficient of determina-tion and hypothesis testing. The results indicates that the examination of the tax and tax penalties have significant impact on taxpayer compliance. Based on these results, audits and tax sanctions can improve taxpayer compliance behavior of the body. The results support Ebimobowei's (2013), Duran's (2009) and Nugroho's (2006), but the results are not suitable with Winerungan's (2012) and Prince's (2014)
\end{abstract}

Keywords: tax inspection, sanctions Taxation and Taxpayer Compliance

\section{PENDAHULUAN}

Sepuluh tahun terakhir nilai anggaran pendapatan dan belanja negara (APBN) terus meningkat. Nota Keuangan Tahun 2015 sebagaimana disampaikan Presiden dalam Pidato Nota Keuangan 2015 di depan para wakil rakyat, Rancangan APBN 2015 ditetapkan sebesar Rp2.019,9 triliun. Sumber utama ditargetkan dari penerimaan pajak sebesar Rp1.370,8 triliun. Target penerimaan dari pajak tersebut meningkat sekitar $10 \%$ dari APBN Perubahan 2014 yang ditetapkan sebesar Rp
1.246,1 (Koran Sindo,2014) Penerimaan sektor pajak cukup tinggi dalam struktur APBN 2015 sehingga pemerintah memerlukan dukungan segenap masya-rakat termasuk wajib pajak untuk merealisasikan APBN 2015 terutama wajib badan.

Data penerimaan pajak nasional bila dibandingkan dengan Produk Domestik Bruto (Tax Ra-tio) masih relatif rendah dibandingkan dengan tax ratio international yang mencapai $20 \%$ pada tahun 2005, tax ratio Indonesia hanya mencapai $12,3 \%$. Tax ratio Indonesia bahkan apabila dibandingkan de-

Korespondensi dengan Penulis:

Pujo Gunarso : Telp. +62 8113651005

Email: pujo.lelly@gmail.com 
ngan negara yang pendapatan per kapitanya rendah masih dibawah Pakistan dan Srilangkah memiliki tax ratio $13,76 \%$ dan 19,8\% (Gunadi, 2005). Data yang ada di Direktorat Jenderal Pajak menunjuk-kan bahwa dari 238 juta penduduk Indonesia, sekitar 44 juta orang dianggap layak membayar pajak. Tetapi dari jumlah itu hanya 8 juta orang yang memenuhi kewajiban perpajakannya. Dari sektor wajib pajak badan, yang tercatat di Direkto-rat Jenderal Pajak terdapat 22.6 juta badan usaha baik yang berdomisili tetap maupun tidak, namun hanya 466 ribu badan usaha yang membayar pajak. Dari data tersebut bisa dilihat bahwa tingkat ke-patuhan wajib pajak (tax compliance) dalam meme-nuhi kewajiban perpajakan masih sangat rendah (Tresno at al, 2013).

Pengertian kepatuhan wajib pajak (tax compliance) adalah kesediaan wajib pajak untuk memenuhi kewajiban perpajakanya sesuai dengan peraturan yang berlaku tanpa melalui pemeriksaan, investigasi dengan seksama, peringatan, ancaman dan berberlakuan sanksi pajak baik hukum maupun administrasi (Simon, dikutip Harinurdin 2009). Kepatuhan wajib pajak adalah faktor yang penting karena fiskus menerapkan sistem self assessment dalam sistem perpajakan di Indonesia. Penerapan self assesment ini akan menjadi efektif apabila kondisi kepatuhan sukarela (voluntary compliance) pada masyarakat telah terbentuk (Damayanti, 2004).

Penelitian Roades (1979) tentang kepatuhan wajib pajak menekankan pada aspek pentingnya kesadaran dan kepatuhan wajib pajak dalam melaporkan pendapatan bersih, karena dari hasil penelitiannya menyimpulkan bahwa wajib pajak seringkali tidak memberikan pelaporan mengenai pendapatan bersihnya. Hasil penelitian ini cukup beralasan karena wajib pajak cenderung menghindari pajak yang tinggi, hasil penelitian ini diperkuat oleh Kirchler (dalam Alabede, 2011: 128) menyatakan bahwa ketika wajib pajak mengeluarkan biaya untuk membayar pajak, terdapat risiko lebih tinggi yang akan membawa kepada ketidak patuhan wajib pajak. Jadi sikap patuh wajib pajak akan membawa biaya kepatuhan wajib pajak semakin tinggi. Learche (1980) juga mengemukakan bahwa kesadaran perpajakan seringkali menjadi kendala dalam masalah pengumpulan pajak dari masyarakat.

Selain faktor biaya kepatuhan masih banyak faktor yang mempengaruhi kepatuhan wajib pajak, maka perlu secara intensif dikaji tentang faktorfaktor yang mempengaruhi kepatuhan wajib pajak, khususnya wajib pajak badan, mengingat kesadaran dan kepatuhan wajib pajak merupakan faktor penting bagi peningkatan penerimaan pajak. Faktor sanksi pajak dan pemeriksaan pajak diduga kuat mempengaruhi kepatuhan wajib pajak untuk melaksanakan kewajiban perpajakanya.

Sanksi berarti hukuman yang dijatuhkan oleh pengadilan kepada pihak yang terbukti bersalah. Penerapan sanksi diterapkan sebagai akibat tidak terpenuhinya kewajiban perpajakan oleh wajib pajak sebagaimana diamanatkan oleh UndangUndang perpajakan. Hasil penelitian Nugroho (2006) menjelaskan sikap wajib pajak terhadap pelaksanaan sanksi denda secara parsial memiliki pengaruh positif yang signifikan terhadap kepatuhan WP. Hal ini menunjukkan bahwa makin tinggi sikap wajib pajak terhadap pelaksanaan sanksi denda maka makin tinggi pula kepatuhan wajib pajak. Menurut Mardiasmo (2003:39) sanksi perpajakan merupakan jaminan bahwa ketentuan peraturan perundang-undangan perpajakan (norma perpajakan) akan dipatuhi. Atau dengan kata lain sanksi perpajakan merupakan alat (preventif) agar wajib pajak tidak melanggar norma perpajakan.

Akan tetapi hasil penelitian Masruroh (2013) menunjukan hasil yang berbeda, melakukan penelitian mengenai pengaruh sanksi perpajakan terhadap kepatuhan wajib pajak, dan hasil penelitiannya menunjukkan bahwa kemanfaatan NPWP, kulitas pelayanan dan sanksi perpajakan secara parsial tidak berpengaruh signifikan ter-hadap kepatuhan wajib pajak. Hasil penelitian ini 


\section{Jurnal Keuangan dan Perbankan | KEUANGAN}

Vol. 20, No.2, Mei 2016: 214-223

juga didukung oleh penelitianya Winerungan (2013) yang menyimpulkan sosialisasi perpajakan, pelayanan fiskus dan sanksi perpajakan tidak berpengaruh terhadap kepatuhan Wajib Pajak Orang Pribadi di KPP Pratama Manado dan KPP Pratama Bitung.

Faktor lainya yang mempengruhi kepatuhan wajib pajak adalah pemeriksaan pajak, riset awal yang berkaitan dengan pemeriksaan dan kepatuhan pajak pada dasarnya menggambarkan model kepatuhan pajak sebagai suatu permainan (simulasi) antara wajib pajak dan insititusi pajak, karena di satu sisi kepatuhan pajak diperhadapkan dengan maksimisasi kesejahteraan wajib pajak (utilitas pribadi) dan di pihak lain institusi berupaya untuk memaksimisasi penerimaan pemerintah melalui strategi audit yang tepat (Beck; 1989, Reiganum; 1985). Hasil penelitian yang terbaru yang dilakukan oleh Samuel (2014) menunjukkan bahwa pemerik-saan pajak sangat mempengaruhi kepatuhan wajib pajak yang diukur menggunakan parameter pen-dapatan pajak.

Reiganum (1985) menguji kepatuhan pajak yang kaitanya dengan sistem self-assessment yang hasilnya menunjukkan bahwa self-assessment yang dilakukan wajib pajak jika dihubungkan dengan strategi audit random dengan tingkat audit yang meningkat akan meningkatkan kepatuhan pajak. Hasil temuan ini sejalan dengan temuan Ghosh dan Crain (1996) yang membuktikan bahwa semakin tinggi audit semakin rendah tingkat ketidakpatuh-an pajak. Analisis yang dilakukan Beck dan Jung (1991) juga membuktikan bahwa pendapatan yang dilaporkan mengalami peningkatan pada saat ada-nya peningkatan probabilita yang diterima dan tarif pinalti.

Beberapa penelitian yang sudah dilakukan sebelumnya ternyata berbeda dengan hasil penelitianya Prince (2014) dilakukan di Nigeria yang menyimpulkan bahwa audit pajak belum membuat dampak besar pada pajak perusahaan yang rendah budaya kepatuhan di Nigeria. Oleh karena itu penting bagi pihak yang berwenang untuk mencari cara yang lebih pragmatis dan efektif meningkatkan dampak audit pajak atas kepatuhan pajak per-usahaan di Nigeria dalam rangka konsolidasi pen-dapatan pemerintah.

Berdasarkan penjelasan dan uraian diatas penulis berpendapat terdapat ketidak konsistenan hasil penelitian tentang faktor yang mempengaruhi kepatuhan wajib pajak terutama faktor sanksi pajak dan pemeriksaan pajak, terdapat research gap yang penulis perlu dikaji atau diteliti lebih lanjut. Penelitian ini menggunakan variabel bebas sanksi pajak dan pemeriksaan pajak dan variabel terikat kepatuhan wajib pajak, dengan lokasi penelitian di KPP kepanjen Kabupaten Malang.

Sistem perpajakan di Indonesia menganut self assesment system, self assesment system adalah satu bentuk sistem pemungutan pajak dimana masyarakat sebagai wajib pajak diberi kepercayaan oleh pemerintah untuk menghitung sendiri besarnya pajak yang terutang dengan mengisi Surat Pemberitahuan (SPT). Sistem ini membuat kepatuhan sukarela (voluntary compliance) wajib pajak menjadi faktor yang sangat penting, karena faktor inilah wajib pajak tergerak untuk melaksanakan kewajibanya melaporkan SPT sampai melakukan pembayaran Penerapan self assesment ini akan menjadi efektif apabila kondisi kepatuhan sukarela (voluntary compliance) pada masyarakat telah terbentuk (Damayanti, 2004).

Berdasarkan Keputusan Menteri Keuangan Nomor 544/KMK.04/2000 yang diubah dengan Keputusan Menteri Keuangan Nomor 235/KMK. 03/2003 jo Keputusan Dirjen Pajak Nomor 550 tahun 2000, wajib pajak dimasukkan dalam kategori wajib pajak patuh apabila memenuhi kriteria sebagai berikut:

1. Tepat waktu dalam menyampaikan surat pem-beritahuan untuk semua jenis pajak dalam dua tahun terakhir.

2. Tidak mempunyai tunggakan pajak untuk semua jenis pajak, kecuali telah memperoleh izin untuk mengangsur atau menunda pembayaran pajak. 
3. Tidak pernah dijatuhi hukuman karena mela- uang karena melanggar peraturan dan hukum yang kukan tindak pidana di bidang perpajakan da- berlaku, sehingga dapat dikatakan bahwa sanksi lam jangka waktu sepulun tahun terakhir. administrasi adalah hukuman negatif kepada or-ang

4. Dalam hal laporan keuangannya diaudit oleh akuntan publik atau BPKP harus dengan pendapat wajar tanpa pengecualian atau dengan pendapat wajar dengan pengecualian sepanjang pengecualian tersebut tidak mempengaruhi laba rugi fiscal

Ketidakpatuhan wajib pajak dapat dilakukan dengan berbagai cara salah satunya adalah dengan sengaja mengurangi jumlah pajak terhutang (Hyman, 1993). Ketidakpatuhan wajib pajak dapat dilakukan dengan cara memanipulasi laporan ke-uangan yang akan digunakan untuk kepentingan pajak. Berdasarkan inilah keputusan kepatuhan pajak atau ketidakpatuhan wajib pajak dapat di-pengaruhi oleh faktor internal individu dan faktor eksternal individu atau dalam beberapa riset disebut dengan faktor nonekonomi dan ekonomi (Alm, 1995).

\section{HIPOTESIS}

\section{Hubungan Sanksi Pajak dengan Kepatuhan Wajib Pajak.}

Pengertian sanksi perpajakan menurut Mardiasmo (2009:57) menyatakan bahwa: Sanksi perpajakan merupakan jaminan bahwa ketentuan peraturan perundang-undangan perpajakan (norma perpajakan) akan dituruti/ditaati/dipatuhi. Atau dengan kata lain sanksi perpajakan meru-pakan alat pencegah (preventif) agar Wajib Pajak tidak melanggar norma perpajakan. Dalam undangundang perpajakan dikenal dua macam sanksi, yaitu sanksi administrasi dan sanksi pidana.

Sanksi pidana adalah hukuman kepada orang yang melanggar peraturan, dan sanksi administrasi adalah hukuman dengan cara membayar yang melanggar peraturan dengan cara mem-bayar uang. Menurut Suyatmin (2004) Undang-undang dan peraturan secara garis besar berisikan hak dan kewajiban, tindakan yang diperkenankan dan tidak diperkenankan oleh masyarakat. Agar undangundang dan peraturan tersebut dipatuhi, maka harus ada sanksi bagi pelanggarnya, de-mikian halnya untuk hukum pajak.

Sikap wajib pajak akan mematuhi pembayaran pajak bila mempertimbangkan sanksi dan denda pajak yang akan lebih membebaninya. Semakin banyak tunggakan pajak yang harus dibayar wajib pajak, maka akan semakin berat bagi wajib pajak untuk melunasinya. Berdasarkan sikap atau pandangan wajib pajak terhadap sanksi denda diduga akan berpengaruh terhadap tingkat kepatuhan wajib pajak dalam memenuhi kewajiban perpa-jakanya. Hal ini sangat relevan jika digunakan se-bagai variabel bebas dalam penelitian ini. Beberapa bukti empiris seperti penelitian, Doran (2009) dan Nugroho (2006) telah menunjukkan bahwa sikap wajib pajak terhadap sanksi berpengaruh positif terhadap kepatuhan wajib pajak. Berdasarkan uraian diatas maka disusun hipotesis:

$\mathrm{H}_{1}$ : Sanksi perpajakan berpengaruh terhadap kepatuhan wajib pajak.

\section{Hubungan Pemeriksaan Pajak dengan Kepatuhan Wajib Pajak.}

Pengertian pemeriksaan pajak adalah serangkaian kegiatan mencari, mengumpulkan, mengolah data dan atau keterangan lainnya untuk menguji kepatuhan pemenuhan kewajiban perpajakan dan tujuan lain dalam rangka melaksanakan ketentuan peraturan perundang-undang perpajakan (Mardiasmo, 2009). 


\section{Jurnal Keuangan dan Perbankan | KEUANGAN}

Vol. 20, No.2, Mei 2016: 214-223

Pengawasan dalam konteks pajak identik dengan pemeriksaan yang dilakukan oleh Dirjen pajak terhadap wajib pajak. Tujuan dilakukan pemeriksaan adalah untuk menghindari kemungkinan terjadinya moral hazard atau adverse selection yang bisa saja dilakukan oleh wajib pajak dalam pengisian SPT. Reiganum (1985) menguji kepatuhan pajak yang kaitanya dengan sistem self-assessment yang hasilnya menunjukkan bahwa self-assessment yang dilakukan wajib pajak jika dihubungkan dengan strategi audit dengan tingkat audit yang meningkat akan meningkatkan kepatuhan wajib pajak. Hasil temuan ini sejalan dengan temuan Ghosh dan Crain (1996) yang membuktikan bahwa semakin tinggi audit semakin rendah tingkat ketidakpatuhan pajak. Analisis yang dilakukan Beck dan Jung (1991) juga membuktikan bahwa pendapatan yang dilaporkan mengalami peningkatan pada saat adanya peningkatan probabilita yang diterima dan tarif pinalti. Berdasarkan uraian tersebut diatas maka disusun hipotesis:

$\mathrm{H}_{2}$ : Pemeriksaan pajak berpengaruh terhadap kepatuhan wajib pajak badan.

\section{METODE}

Jenis penelitian ini adalah penelitian kausalitas, Sanusi (2011:14) menjelaskan penelitian kausalitas adalah desain penelitian yang disusun untuk meneliti kemungkinan adanya hubungan sebab akibat antar variabel. Pendekatan Penelitian ini dilakukan dengan menggunakan field ressearch yakni pengamatan langsung terhadap obyek yang diteliti guna mendapatkan data yang relevan de-ngan pengisian kuesioner dan analisis penelitian menggunakan analisis kuantitatif, yaitu mengguna-kan analisis data secara mendalam dalam bentuk angka.

Variabel dependent ( $\mathrm{Y}$ ) pada penelitian ini adalah Kepatuhan Wajib Pajak badan dan variabel independent atau variabel bebas pada penelitian ini adalah Pemeriksaan Pajak $\left(X_{1}\right)$ dan Sanksi Perpa- jakan $\left(\mathrm{X}_{2}\right)$. Variabel dalam penelitian ini diukur de-ngan menggunakan kuesioner dengan pengukuran variabel menggunakan skala likert 1 sampai dengan 5 poin.

Variabel dependent (Y) adalah Kepatuhan Wajib Pajak badan. Kepatuhan wajib pajak badan adalah suatu tindakan patuh dan sadar yang dilakukan oleh wajib pajak dalam melaksanakan kewajiban perpajakannya. Variabel independent adalah Pemeriksaan Pajak $\left(\mathrm{X}_{1}\right)$ Pemeriksaan Pajak adalah kegiatan mengumpulkan atau mencari data wajib pajak untuk menguji kepatuhan wajib pajak badan dalam memenuhi kewajiban perpajakannya. Variabel ini terdiri dari 19 item pertanyaan yang dijawab dengan Jawaban dari responden digunakan untuk menentukan seberapa besar pengaruh pemeriksaan pajak terhadap kepatuhan wajib pajak badan. Variabel sanksi perpajakan $\left(\mathrm{X}_{2}\right)$, sanksi perpajakan adalah kondisi dimana wajib pajak yang melanggar peraturan perpajakan atau tidak patuh dalam melaksanakan kewajiban perpajakannya akan dikenakan sanksi perpajakan. Variabel ini ter-diri dari 8 item pertanyaan yang dijawab respon-den digunakan untuk menentukan seberapa besar pengaruh sanksi perpajakan terhadap kepatuhan wajib pajak badan.

Responden dalam penelitian ini adalah pemeriksa pajak dan account representative pada Kantor Pelayanan Pajak Pratama Kepanjen. Dalam hal ini sampel yang diambil yaitu seluruh populasi pemeriksa pajak dan account representative pada KPP Pratama Kepanjen. Sumber data yang diperlukan dalam penelitian ini adalah data primer, dengan cara menyebarkan kuesioner dan melakukan wawancara secara langsung dengan pihak-pihak yang berhubungan dengan penelitian yang dilakukan.

Metode analisis yang digunakan dalam penelitian ini pertama uji validitas dan uji reliabilitas data. Uji validitas digunakan untuk mengukur tingkat validitas suatu item pertanyaan dan menentukan apakah suatu item layak digunakan atau tidak. Uji validitas pada penelitian ini adalah meng- 
gunakan Pearson Correlation yaitu dengan menghitung korelasi antara skor masing-masing butir pertanyaan dengan total skor pertanyaan. Kriteria yang digunakan apabila tingkat signifikansi kurang dari 0,05 maka butir pertanyaan tersebut valid demikian pula sebaliknya. Uji reliabilitas digunakan untuk mengetahui konsistensi alat ukur, apakah alat pengukuran yang digunakan dapat diandal-kan. Di dalam penelitian ini uji reliabilitas dila-kukan dengan menggunakan alpha chronbach, varia-bel penelitian dapat dinyatakan reliabel apabila indeks alpha lebih dari 0,6. Analisis yang kedua ui asumsi klasik, uji asumsi klasik digunakan untuk menguji bahwa analisis regresi bebas masalah-masalah asumsi klasik seperti normalitas, multi-kolonieritas, autokolerasi dan heteroskedastisitas (Ghozali, 2009).

Metode analisis berikutnya adalah Untuk mengestimasi besarnya pengaruh variabel independen (pemeriksaan pajak dan sanksi perpajakan) terhadap variabel dependen (kepatuhan wajib pajak badan). Dapat menggunakan rumus analisis regresi berganda berikut: $=+11+22+$ Notasi:

Y $\quad$ : kepatuhan wajib pajak

: konstanta

$b_{1}$ dan $b_{2}:$ koefisien regresi

$\mathrm{X}_{1} \quad$ : pemeriksaan pajak

$\mathrm{X}_{2} \quad$ : sanksi perpajakan

: error

Pengujian hipotesis yang gunakan uji $\mathrm{F}$ untuk mengetahui apakah variabel-variabel independen secara simultan berpengaruh signifikan terhadap variabel dependen. Derajat kepercayaan yang digu-nakan adalah 0,05. Analisis Koefisiensi Determinasi (KD) digunakan untuk melihat seberapa besar variabel independen $(X)$ berpengaruh terhadap variabel dependen $(Y)$ yang dinyatakan dalam per-sentase.
HASIL

\section{Gambaran Umum Responden Penelitian}

Sampel yang digunakan dalam penelitian ini berjumlah 40 responden atau pegawai KPP Pra-tama Kepanjen. Hasil dari kuesioner tersebut dapat dilihat pada tabel berikut.

Tabel 1 Karakteristik Responden Menurut Jenis Kelamin

\begin{tabular}{|l|c|c|}
\hline Jenis Kelamin & $\begin{array}{c}\text { Banyak } \\
\text { Responden }\end{array}$ & Persentase (\%) \\
\hline Laki-laki & 22 & $55 \%$ \\
\hline Perempuan & 18 & $45 \%$ \\
\hline Total & 40 & $100 \%$ \\
\hline
\end{tabular}

Pada tabel diatas dilihat bahwa responden ter-banyak laki-laki yaitu 22 responden (55\%) sedangkan 18 responden (45\%) berjenis kelamin perempuan.

Tabel 2 Karakteristik Responden Menurut Lama Kerja

\begin{tabular}{|l|c|c|}
\hline \multicolumn{1}{|c|}{ Lama Kerja } & $\begin{array}{c}\text { Banyak } \\
\text { Responden }\end{array}$ & Persentase (\%) \\
\hline 2-15 tahun & 30 & $75 \%$ \\
\hline 16-34 tahun & 10 & $25 \%$ \\
\hline Total & 40 & $100 \%$ \\
\hline
\end{tabular}

Pada tabel diatas dapat dilihat bahwa responden yang lama kerja di KPP 2-15 tahun sebanyak 30 responden (75\%), lama kerja 16-34 tahun sebanyak 10 orang $(25 \%)$.

\section{Uji Validitas dan Reliabilitas}

Berdasarkan uji validitas dengan uji korelasi product moment pearson menunjukan variabel kepatuhan menunjukan bahwa 6 item pertanyaan yang diuji memiliki tingkat signifikansi $<0,05$, maka di dalam item variabel kepatuhan wajib pajak badan (Y) adalah valid dengan demikian dapat di-pakai dalam penelitian. Berdasarkan uji validitas variabel pemeriksaan pajak $\left(X_{1}\right)$ menunjukan bahwa 


\section{Jurnal Keuangan dan Perbankan | KEUANGAN}

Vol. 20, No.2, Mei 2016: 214- 223

19 item pertanyaan yang diuji memiliki tingkat signifikansi $<0,05$, maka di dalam item variabel pemeriksaan pajak $\left(X_{1}\right)$ adalah valid dengan demikian dapat dipakai dalam penelitian. Berdasarkan uji validitas variabel sanksi perpajakan menunjukan bahwa 8 item pertanyaan yang diuji memiliki tingkat signifikansi $<0,05$, maka di dalam item variabel sanksi perpajakan $\left(\mathrm{X}_{2}\right)$ adalah valid dengan demikian dapat dipakai dalam penelitian. Berdasarkan uji reliabilitas dengan menghitung nilai koefisien Alpha Cronbach dapat diketahui bahwa semua variabel mempunyai indeks alpha lebih besar dari 0,6. Jadi berdasarkan uji reliabilitas instumen yang ada layak untuk dipergunakan.

\section{Pengujian Asumsi Klasik Regresi}

Pengujian normalitas dilakukan dengan meng-gunakan Normal P-P Plot of Regressions Standardized Residual. Pengujian yang telah dilakukan menun-jukan bahwa data menyebar di sekitar garis di-agonal dan mengikuti arah garis diagonal maka model regresi dalam penelitian ini telah memenuhi asumsi normalitas. Pengujian multikolinearitas menunjukan bahwa untuk ketiga variable indepen-dent diperoleh nilai tolerance $>0,1$ dan nilai VIF $<10$ dengan demikian maka model regresi di dalam penelitian ini dapat dinyatakan bebas multikoli-nearitas. Pengujian autokorelasi menggunakan besaran Durbin-Watson, tabel model Summary hasil uji autokorelasi menunjukan bahwa hasil dari penelitian ini diperoleh nilai D-W sebesar 1,542, karena angka D-W di antara angka -2 sampai +2 berarti bahwa dalam model regresi ini tidak terdapat autokorelasi. Masalah homokesdastisitas di deteksi dengan Scatter Plot Regressions Studentized Residual. Hasil dari uji heterokesdastisitas yang disajikan dalam scatterplot menunjukan tidak ada pola yang jelas, serta titik-titik menyebar di atas dan di bawah sumbu Y maka dalam model pene-litian ini tidak terjadi heterokesdastisitas.

\section{Analisis Data}

\section{Pengujian Ketepatan Model/Goodness of Fit Model (Uji F)}

Hasil pengujian (Uji F) menunjukkan bahwa nilai $\mathrm{F}$ sebesar 22,991 dan nilai probabilitas ( $p$ value) sebesar 0,000 yang signifikan pada sebesar $5 \%(0,00$ $<0,05)$ maka dapat diartikan bahwa variabel independen yang terdiri dari pemeriksaan pajak dan sanksi perpajakan yang diformulasikan dalam model penelitian ini berpengaruh terhadap variabel dependen (kepatuhan). Maka dengan demikian dapat disimpulkan bahwa model yang digunakan dalam model penelitian ini modelnya sudah tepat (goodness of fit model).

\section{Koefisien Determinasi}

Nilai koefisien determinasi sebesar 0,530 $\left(R^{2}=0,530\right)$. Hal ini berarti bahwa $53,0 \%$ istimasi kepa-tuhan dapat dijelaskan oleh ketdua variabel inde-penden yaitu pemeriksaan pajak dan sanksi perpajakan. Sedangkan sisanya $47,0 \%$ dijelaskan oleh faktor atau variabel yang lain diluar model regresi.

Tabel: 3 Hasil Analisis Regresi Berganda

\begin{tabular}{lllll}
\hline Variabel & $\begin{array}{c}\text { Koefisien } \\
\text { Regresi }\end{array}$ & Std. Error & Nilai t & Nilai $\boldsymbol{p}$ \\
\hline & & & & \\
Pemeriksaan Pajak & .454 & .048 & $3.035 .004 \square)$ \\
Sanksi Perpajakan & .357 & .127 & $2.387 .022 \square)$ \\
\hline
\end{tabular}

*). Secara statistik signifikankan pada level á sebesar 5\%

\section{Pengujian Hipotesis}

Berdasarkan hasil pengujian $\mathrm{H}_{1}$ tersebut pada tabel 3 menunjukkan bahwa pemeriksaan pajak secara statistik signifikan pada level $=5 \%$, sedang-kan nilai koefisien regresi sebesar 0,454 , standar error 0,048 , nilai t hitung sebesar 3,035 dan nilai $p$ 
Value 0,004 . Hasil tersebut menunjukan $p$ value < $0,05(0,004<0,05)$ Dengan demikian, maka sesuai dengan hipotesis atau tanda koefisien yang positif menunjukkan bahwa semakin sering dilakukan pemeriksaan pajak maka kepatuhan wajib pajak akan meningkat (semakin patuh), dan sebaliknya jika kuantitas pemeriksaan pajak semakin dikurangi maka perilaku patuh wajib pajak semakin menurun.

Berdasarkan hasil pengujian $\mathrm{H}_{2}$ tersebut pada tabel 3 menunjukkan bahwa sanksi perpajak-an secara statistik signifikan pada level sebesar 5\% sedangkan nilai koefisien regresi sebesar 0,357 dan standar error sebesar 0,127, t hitung sebesar 2,387 dan nilai $p$ Value 0,022 sehingga berdasarkan hasil tersebut menunjukan $p$ Value $<0,05(0,022<0,05)$. Maka dapat disimpulkan $\mathrm{H}_{2}$ diterima. Dengan demikian, sesuai dengan $\mathrm{H}_{2}$ dapat diartikan bahwa sesuai dengan hipotesis atau tanda koefisien yang positip menunjukkan bahwa semakin besar sanksi perpajakan maka kepatuhan waijb pajak semakin meningkat, dan sebaliknya jika sanksi perpajakan menurun (diperingan) maka perilaku kepatuhan wajib pajak juga semakin menurun (semakin tidak patuh).

\section{PEMBAHASAN}

\section{Pengaruh Pemeriksaan Pajak terhadap Kepatuhan Wajib Pajak}

Penelitian ini berhasil menemukan bahwa pemeriksaaan pajak secara statistik berpengaruh positif dan signifikan terhadap kepatuhan wajib pajak (menerima $\mathrm{H}_{1}$ ). Sesuai dengan arah koefisiennya yang positif maka hal ini mengindikasikan bahwa apabila terjadi kenaikan kuantitas pemeriksaan pajak maka akan mengakibatkan peningkatan perilaku patuh wajib pajak. Hasil penelitian ini sesuai dengan hasil penelitianya Ebimobowei (2013), yang menjelaskan pemeriksaan pajak ada-lah salah satu strategi yang digunakan oleh peme-rintah Nigeria untuk upaya meningkatkan perilaku patuh wajib pajak dan juga mendukung penelitianya Samuel dan Jean (2014), yang menjelaskan bahwa pemeriksaan pajak sangat berpengaruh terhadap jumlah pendapatan pajak yang yang dikumpulkan oleh pemerintah Rwanda, artinya dengan pembayaran pajak semakin meningkat oleh wajib pajak dapat diartikan perilaku kepatuhan wajib pajak juga meningkat.

\section{Pengaruh Sanksi Pajak terhadap Kepatuhan Wajib Pajak}

Penelitian ini berhasil menemukan pengaruh yang signifikan sanksi pajak terhadap kepatuhan wajib pajak. Sesuai dengan arah koefisiennya yang positip maka hal ini menunjukkan bahwa semakin besar sanksi perpajakan maka perilaku kepatuhan wajib pajak semakin meningkat. Sesuai dengan hasil penelitianya Doran (2009) yang menjelaskan sanksi pajak atau denda pajak mempunyai hubung-an yang kuat terhadap kepatuhan wajib pajak, bah-kan wajib pajak yang berani menggelapkan pajak karena sanksi pajak kecil bahkan tidak ada sanksi pajak. Juga didukung oleh hasil penelitianya Nugroho (2006), yang menjelaskan sikap wajib pajak terhadap pelaksanaan sanksi denda secara parsial memiliki pengaruh positif yang signifikan terhadap kepatuhan wajib pajak. Hal ini menunjukkan bahwa makin tinggi sikap wajib pajak terhadap pelaksanaan sanksi denda maka makin tinggi pula kepatuhan WP.

\section{KESIMPULAN}

Berdasarkan hasil pengujian seluruh hipotesis, maka secara keseluruhan penelitian ini dapat memberikan bukti empiris bahwa pemeriksaan pajak dan sanksi perpajakan berpengaruh positif dan signifikan terhadap perilaku patuh wajib pajak. Dengan demikian semakin sering dilakukan pemeriksaan pajak dan semakin besar sanksi perpajakan yang diberlakukan maka perilaku patuh wajib 


\section{Jurnal Keuangan dan Perbankan | KEUANGAN}

Vol. 20, No.2, Mei 2016: 214-223

pajak semakin meningkat. Hal tersebut menunjukkan bahwa pemeriksaan pajak dan sanksi perpajakan seharusnya menjadi perhatian fiskus dalam upaya meningkatkan pendapatan pajak negara.

\section{Saran}

Bagi fiskus yang bertanggung jawab menarik pajak dari masyarakat untuk membiayai pembangunan nasional sebaiknya mempertimbangkan pemeriksaan pajak dan sanksi perpajakan ketika terjadi penurunan penerimaan pajak, hendaknya meninjau ulang kebijakan tentang pemeriksaan pajak dan sanksi pajak yang diberlakukan, apakah perlu ditingkatkan. Bagi peneliti selanjutnya dapat menggunakan variabel penelitian yang lain, variabel yang berpengaruh terhadap kepatuhan wajib pajak lebih banyak lagi baik yang berkaitan dengan faktor intern wajib pajak (sikap perilaku) maupun faktor ekstern wajib pajak yang berkaitan dengan faktor sosial ekonomi wajib pajak.

\section{DAFTAR PUSTAKA}

Alm James., I.,Sanchez., dan Ana De Juan,.1995. Economicand Non-economic Factors in Tax Com-pliance. KYKLOS, 48(1): 8-18.

Anonin, 2014, Target Pajak Naik Terus, Koran Sindo Selasa,19 Agustus 2014 “ 16:48

WIB http://nasional.sindonews.com/read/892935/ 16/target-pajak-naik-terus 1408441700

Beck, P., J dan., W. Jung. 1991. Experimental Evidence on Tax Payer Reporting Under Uncertainty. The Ac-counting Review, 66: 535 - 558.

Darmayanti, Theresia Woro, 2004. Pelaksanaan Self Assesment System Menurut Wajib Pajak (Studi Kasus pada Wajib Pajak Badan Salatiga). Jurnal Ekonomi dan Bisnis. Volume X No. 1, 109 - 128.

Doran, Michael, 2009, Penalties AndTax Comppliance, Harvard Journal onLegislation 111-161. Vol. 46. http:/ /scholarship.law.georgetown.edu/facpub/915

Ebimobowei, Appah. 2013.A Causality Analysis between Tax Audit and Tax Compliance in Nigeria. Euro- pean Journal of Business and Management. Vol.5. No.2. p.107-120.

Guandi, 2005, Indonesian Taxation ; A Reference Guide, Jakarta: Multi Utama Publishing Ghosh Dipankar dan Crain L., C. 1996. Experimental Investigation of Ethical Standards and Perceived Probability of Audit on Intentional Noncompliance.Behavioral Research in Accounting, 8(Supplement 1996): 219-244

Harinurdin, Erwin.2009."Perilaku kepatuhan Wajib Pajak". Bisnis \& Birokrasi, Jurnal Ilmu Administrasi dan Organisasi, Mei-Agustus 2009, hlm. 96-104 Volume 16, Nomor 2

Hyman, D., N. 1993. Public Finance: A Contemporary Application of Theory To Policy(Fourth ed.): The Eryden Press

Iswahyudi. 2005. Faktor- Faktor yang Mempengaruhi Penerimaan Pajak, Berita Pajak. Jakarta

Lerche, Pletrich. 1980. Efficency of taxtion in indonesia. Bies. VOL. 16 No, 1, halaman 34-35.

Masruroh, Siti dan Zulaikha. 2013. Pengaruh Kemanfaaatan NPWP, Pemahaman Wajib Pajak, Kualitas Pelayanan, Sanksi Perpajakan Terhadap Kepatuhan Wajib Pajak (Studi Empiris Pada WPOP Di Kabupaten Tegal). Diponegoro Journal Of Accounting Volume 2, Nomor 4.

Mardiasmo. 2009. Perpajakan. Edisi Revisi 2009.

Yogyakarta. Penerbit Andi

Mardiasmo. 2003. Perpajakan. Edisi Revisi. Yogyakarta: Andi.

Nugroho, Agus Jatmiko 2006. Pengaruh Sikap Wajib Pajak Pada Pelaksanaan Sanksi

Denda,Pelayanan Fiskus, dan Kesadaran Perpajakan Terhadap Kepatuhan Wajib Pajak. Tesis: Magister Akuntansi Program Pascasarjana Universitas Dipenogoro

Prince, Kennedy. 2014. Impact of Tax Audit on Tax Compliance Negeria.International J ournal of Business and Social Science Vol. 5 No. 9; August 2014

Republik Indonesia, Keputusan Menteri Keuangan No. 235/KMK. 03/2003 tentang

Perubahan Keputusan Menteri Keuangan No. 544/ KMK. 04/2000 tentang Kriteria Wajib Pajayang 
Dapat Diberikan Pengembalian Pendahuluan Kelebihan Pembayaran Pajak.

Reinganum, Marc R. 1985. “ The Anomalous Stock Market Behaviour of Small Firms in January: Empiri-cal Tests for Tax-Loss Selling Effects," Journal of Financial Economics, vol.12, no.1 (June): 89-104.

Samuel dan Jean, 2014, The Impact of Taxpayers Financial Statements Audit on Tax

Revenue Growth, International Journal of Business and Eco-nomic Development (IJBED) Vol. 2 Number 2 July 2014www.ijbed.org A Journal of the Academy of Busi-ness and Retail Management (ABRM).

Sanusi, A. 2011. Metodologi Penelitian Bisnis, Salemba Empat. Jakarta.

Suyatmin, 2004, Pengaruh Sikap Wajib Pajak Terhadap Kepatuhan Wajib Pajak Dalam Pembayaran Pajak Bumi dan Bangunan: Studi Empiris di Wilayah KP PBB Surakarta, Tesis Program Pasca Sarjana Mag-ister Sains Akuntansi Universitas Diponegoro.
Tresno,. Pahala, Indra,. \& Rizky, Selvy Ayu, 2013, Pengaruh Persepsi Penerapan Sistem e-Filing Terhadap Tingkat Kepatuhan Wajib Pajak Badan Dengan Perilaku Pajak Sebagai Variabel Interven-ing Dan Biaya Kepatuhan Sebagai Variabel Moderasi. Prosiding Simposium Nasional Perpajakan 4.

Uppal, J. S. 2005.Kasus Penghindaran Pajak di Indonesia. Economic Review Journal, 201:1 - 5.

Winerungan, Oktaviane L, 2013. Sosialiasai Perpajakan, Pelayanan Fiskus Dan

Sanksi Perpajakan Terhadap Kepatuhan WPOP di KPP Manado dan KPP Bitung. Fakultas Ekonomi dan Bisnis, Jurusan Akuntansi, Universitas Sam Ratulangi Manado. Jurnal Emba Vol.1No.3September 2013, hal 960-970 
